\title{
Effect of diamino((2-)(2- aminoethyl)amino)ethyl)amino)methanethiol on the Corrosion Resistance of Carbon Steel in Simulated Concrete Pore Solutions
}

\author{
Tao Ji ${ }^{1,2}$, Fubin Ma ${ }^{3}$, Dalin Liu ${ }^{4}$, Xiaoying Zhang ${ }^{3}$, Xiong Zhang ${ }^{1}$, Qi Luo ${ }^{1,5, *}$ \\ ${ }^{1}$ School of Materials Science and Engineering, Tongji University, Shanghai, 201804, China \\ ${ }^{2}$ China Construction Eighth Engineering Division Co. Ltd, Shanghai 200135, China \\ ${ }^{3}$ Institute of Oceanology, Chinese Academy of Sciences, Qingdao, 266071, China \\ ${ }^{4}$ School of Civil Engineering and Architecture, Nanchang University, Nanchang, 330031, China \\ ${ }^{5}$ School of Materials Science and Engineering, Nanchang University, Nanchang, 330031, China \\ *E-mail: luoqi@ncu.edu.cn
}

doi: $10.20964 / 2018.06 .56$

Received: 9 March 2018 / Accepted: 10 April 2018 / Published: 10 May 2018

\begin{abstract}
Diamino((2-((2-aminoethyl)amino)ethyl)amino)methanethiol was synthesized, and its inhibition performance on carbon steel in simulated concrete pore solutions was studied by means of electrochemical techniques, scanning electron microscopy and quantum chemical calculation. The results showed that the inhibiting performance of this inhibitor was excellent, and the obtained inhibition efficiencies from different experiments were in good agreement from different experiments. Polarization curves revealed that the inhibitor acted as a mixed-type inhibitor, suppressing the anodic and cathodic corrosion reaction processes of carbon steel by forming a protective film on its surface. Electrochemical impedance spectroscopy measurements revealed that the charge transfer process in the corrosion reaction was retarded because of the protection film formed on the surface of the carbon steel. The absorption mechanism of the inhibitor molecules on the carbon steel surface was analysed using a quantum chemical study.
\end{abstract}

Keywords: corrosion inhibitor; carbon steel; electrochemical techniques; simulated concrete pore solutions; chloride

\section{$\underline{\text { FULL TEXT }}$}

(C) 2018 The Authors. Published by ESG (www.electrochemsci.org). This article is an open access article distributed under the terms and conditions of the Creative Commons Attribution license (http://creativecommons.org/licenses/by/4.0/). 